\title{
Detecting Low-Intensity Fires in East Asia Using VIIRS Data: An Improved Contextual Algorithm
}

\author{
Ning Zhang, Lin Sun *, Zhendong Sun and Yu Qu
}

Citation: Zhang, N.; Sun, L.; Sun, Z.; $\mathrm{Qu}, \mathrm{Y}$. Detecting Low-Intensity Fires in East Asia Using VIIRS Data: An Improved Contextual Algorithm. Remote Sens. 2021, 13, 4226. https:// doi.org/10.3390/rs13214226

\section{Academic Editors:}

Alfonso Fernández-Manso and Carmen Quintano

Received: 16 September 2021

Accepted: 17 October 2021

Published: 21 October 2021

Publisher's Note: MDPI stays neutral with regard to jurisdictional claims in published maps and institutional affiliations.

Copyright: (C) 2021 by the authors. Licensee MDPI, Basel, Switzerland. This article is an open access article distributed under the terms and conditions of the Creative Commons Attribution (CC BY) license (https:/ / creativecommons.org/licenses/by/ $4.0 /)$.
College of Geodesy and Geomatics, Shandong University of Science and Technology, Qingdao 266590, China; 201983020108@sdust.edu.cn (N.Z.); 201983020071@sdust.edu.cn (Z.S.); 202083020058@sdust.edu.cn (Y.Q.)

* Correspondence: sunlin6@126.com

Abstract: The Visible Infrared Imaging Radiometer Suite (VIIRS) fire detection algorithm mostly relies on thermal infrared channels that possess fixed or context-sensitive thresholds. The main channel used for fire identification is the mid-infrared channel, which has relatively low temperature saturation. Therefore, when the high temperature of a fire in this channel is used for initial screening, the threshold is relatively high. Although screening results are tested at different levels, few small fires will be lost under these strict test conditions. However, crop burning fires often occur in East Asia at a small scale and relatively low temperature, such that their radiative characteristics cannot meet the global threshold. Here, we propose a new weighted fire test algorithm to accurately detect small-scale fires based on differences in the sensitivity of test conditions to fire. This method reduces the problem of small fires being ignored because they do not meet some test conditions. Moreover, the adaptive threshold suitable for small fires is selected by bubble sorting according to the radiation characteristics of small fires. Our results indicate that the improved algorithm is more sensitive to small fires, with accuracies of $53.85 \%$ in summer and $73.53 \%$ in winter, representing an $18.69 \%$ increase in accuracy and a $28.91 \%$ decline in error rate.

Keywords: visible infrared imaging radiometer suite; active fire identification; mid-infrared screening; weighted fire algorithm; adaptive threshold

\section{Introduction}

Fires, both natural and man-made, occur frequently and possess strong breaking speeds. The harmful gases and smoke released during combustion have serious impacts on the climate and air quality [1-3]. In East Asia, the first step in crop production within a year is to burn the remaining plants from the preceding year and remove the sundries from the field. These agricultural fires are characterized by small areas and low temperatures [4]. Using recent remote sensing algorithms, the detection of such small fires is difficult because the radiation emitted cannot be easily distinguished from non-fire background radiation. The small fires mentioned in this study are mostly caused by burning of crops by humans and are characterized by small area and short combustion time. To date, most fire detection algorithms have been designed for global application. Therefore, the present study aims to design and evaluate a small-fire detection algorithm suitable for crop combustion in East Asia and compare its performance with global products. In this study, we review the most advanced remote sensing technology for detecting small and cold fires and propose an improved algorithm using Visible Infrared Imaging Radiometer Suite (VIIRS) observation data.

Satellite data are widely used for detecting active fires and biological combustion. Over the years, with the validation and improvement of detection algorithms, fire products have reached a mature level of application [5-9]. The common means of satellite remote sensingbased fire monitoring include the differences in brightness temperature in the thermal infrared band, reflection in the visible and near-infrared bands, and the combination of these two types of information. NOAA's advanced very high-resolution radiometer 
(AVHRR) and NASA's Medium Resolution Imaging Spectroradiometer (MODIS) data provide high-quality fire products. Different satellite datasets have been utilized to support a variety of active fire and biomass combustion products and applications. AVHRR utilizes the mid infrared and thermal infrared bands to locate the maximum thermal radiation of fire, so as to automatically identify the fire activity area. The algorithm considers the mid infrared threshold on the basis of channel saturation and connects the fire area with the background warm surface and thermal infrared $(10.3-11.3 \mu \mathrm{m})$. These are further separated to ensure that they are not affected by clouds and water bodies [10]. MODIS data are implemented to generate the currently validated best active fire detection products MOD14 and myd14 (from Terra and aqua spacecraft, respectively), with a spatial resolution of $1 \mathrm{~km}$ [11]. At present, the most commonly used fire detection algorithms in MODIS are threshold and contextual methods [12,13]. The major algorithm of MODIS fire products, the contextual method, identifies fires by the difference between the radiation of a measured point and background radiation. However, the background radiation is obtained from the background window composed of the points surrounding the measured point. In this method, the brightness temperature of the mid-infrared and thermal infrared bands of a fire pixel is significantly higher than that of the pixels around it, and the fire pixel is detected based on this difference [14-16]. However, due to the reduced pixel resolution of MODIS and AVHRR, MODIS and AVHRR fire detection ability will decrease rapidly at the angle from the lowest point. MODIS may overlook the observation results of fires that can be detected at the lowest point (at the angle from the lowest point). In addition, its insensitivity to small fires leads to the deviation of fire emission estimation [17,18]. A visible infrared imaging radiometer (VIIR) is a sensor mounted on a National Polar-orbiting Partnership satellite. It is a scanning imaging radiometer that can collect radiation images of land, the atmosphere, ice, and oceans in the visible and infrared bands. As a result, VIIRS fire products provide more detailed spatial information, and this improved resolution can compensate for the omission of small fires [19]. VIIR suite fire products are tested using the contextual method, which mostly includes a preliminary threshold for identifying potential fire pixels, a contextual test for confirming fires in potential fire pixels, and thresholding for rejecting false alarms [20]. Considering that the infrared and thermal infrared channels in VIIRS data are different from the relatively low-saturation temperatures of other satellites, the initial threshold cannot be set too low for global applications. In addition, the testing of brightness temperature during initial screening in the contextual method established by VIIRS fire products is increased. Such an increase in the brightness temperature threshold conditions can theoretically meet the band characteristics of the VIIRS data; however, it also creates unstable factors.

The three products use the test concept of contextual method to evaluate fire with background radiation and modify the algorithm adaptively according to the difference of sensors. Theoretically, the contextual method has reached a mature level of application and has become the most developed and widely used fire detection algorithm in the past decade [5,6]. Moreover, this global fire detection algorithm has several weaknesses, including: (1) the determination of a fixed threshold for potential fire pixels, (2) ignoring the sensitivity difference of test conditions, and (3) spectral difference of small fire [21]. Small and cold fires are often ignored because of the particularity of the region and fire radiation, while cryogenic organisms exhibit different characteristics [22,23].

The contextual VIIRS-based method is still a hierarchical model. After the initial conditions are met, the second part of the judgment is performed. An increase in the test threshold results in the loss of some fire information when the model takes the intersection. Moreover, the characteristic parameters of special, low-temperature fire pixels are ignored. In the second part of the test, it is assumed that the surrounding non-flame pixels have similar brightness temperatures, which is inappropriate in heterogenous areas. In the second part of the test, it is difficult to compare the brightness temperature of surrounding pixels as the complete judgment condition, which is inappropriate under the radiation 
characteristics of small fires. In short, reflected solar radiation reduces the contrast between fire pixels and non-fire background pixels [24].

For the reasons outlined above, VIIRS fire products can be improved by changing the threshold for identifying potential fire pixels, and by adjusting the overall test conditions and its weight. In this study, we analyzed the weight of test conditions according to the differences in the sensitivity of test conditions to fires, proposed a new fire probability algorithm created by the sensor, and calibrated a new global optimal probability threshold to reduce false positive errors in fire detection. The achieved increase in the weights of test conditions effectively reduced the problem of small fires being ignored during model-level screening.

\section{Input Data}

VIIRS is a remote-sensing instrument flying on the S-NPP and NOAA-20 (also referred to as JPSS-1) satellite platforms [25]. VIIRS has 22 channels, with a nominal spatial resolution of $375 \mathrm{~m}$ in the five imagery bands (I-bands) and $750 \mathrm{~m}$ in 16 moderate resolution bands (M-bands), covering a spectral range from $0.412 \mu \mathrm{m}$ to $12.01 \mu \mathrm{m}$. In addition, the unique DNB is included on VIIRS, that measures radiances over a broadband spectrum from 0.4 to $0.9 \mu \mathrm{m}$ with a nominal spatial resolution of $750 \mathrm{~m}$ [26,27]. It can be downloaded from the Earthdata Search website of the United States National Aeronautics and Space Administration (https://search.earthdata.nasa.gov). The spectral and spatial characteristics of the VIIRS channels utilized in this study are listed in Table 1.

Table 1. Spectral and spatial characteristics of VIIRS channels.

\begin{tabular}{ccc}
\hline Channel No. & Band Range $(\mu \mathrm{m})$ & Dynamic Range $(\rho$ OR K) \\
\hline I4 & $3.55-3.93$ & $180-367$ \\
I5 & $10.5-12.4$ & $180-380$ \\
\hline
\end{tabular}

\section{Fire Detection Algorithm}

The major driving factors of the fire detection algorithm proposed in this study are VIIRS I4 and I5. The spectral response of channel I4 ranges from 3.55-3.93 $\mu \mathrm{m}$, centered at $3.74 \mu \mathrm{m}$. Channel I5 is centered at $10.5-12.4 \mu \mathrm{m}$ and is the major channel of comparison with I4. The remaining three I-band channels (I1, I2, and I3) cover the visible light $(0.6-0.68 \mu \mathrm{m})$, near-infrared $(0.846-0.885 \mu \mathrm{m})$, and short-wave infrared $(1.58-1.64 \mu \mathrm{m})$ spectra to support the recognition of clouds, solar scintillation, and water bodies in fire detection algorithms [28,29]. Channel I4 provides the millimeter-wave imaging radiometer brightness temperature, which can be utilized as the main parameter in active fire detection. The wavelength range of the channel has a peak spectral radiation for blackbody emissions at temperatures between 737 and $817 \mathrm{~K}$. However, the saturation temperature of the channel is $367 \mathrm{~K}$, and improved spatial resolution leads to frequent fire pixel saturation. Therefore, this is considered to be the most important channel feature affecting the development of the active excitation algorithm in this dataset. The VIIRS fire product model was originally composed of a two-channel temperature test and stepped judgment. The first part of the test involved the VIIRS channels I4 and I5. The brightness temperature was initially required to meet the initial threshold. Further, the differences in the spatial contrast of the brightness temperatures of the VIIRS channels were analyzed in order to capture areas of abnormally high temperature. Based on similar methods to those utilized in the International Geosphere Biosphere Program and Moderate Resolution Imaging Spectroradiometer fire products, pixels containing optically thick clouds were independently classified as part of the fire algorithm [30], eliminating clouds, desert and coastal boundaries, and solar flares.

Visible Infrared Imaging Radiometer Suite active fire detection and characterization products provide a good foundation for fire identification but ignore the fact that the lowtemperature state of small fires in channels I4 and I5 does not meet the initial threshold. The 
difference in fire sensitivity under different test conditions is not taken into consideration. Therefore, the probability of variation in brightness temperature must be modified to capture small, low-temperature fires by adding the proposed contrast test to eliminate the entrustment error from specific surfaces with significant contrasts.

In this study, we mostly focused on test conditions and threshold selection, analyzed the feasibility of test conditions, the optimal threshold range, and the sensitivity of the new threshold. Furthermore, we resolved the instability of the test conditions and error caused by the use of a fixed threshold, so as to reduce false positives. Weight analysis of the fire test conditions serves as the core of the improved algorithm and therefore, different test condition weights were employed for two seasons (winter and summer). Additionally, as the original fire probability threshold is outdated, our approach represents an improvement in the probability of algorithm accuracy. However, a global optimal fire probability threshold must also be proposed for the new algorithm.

\subsection{Contextual Concept}

The contextual analysis implemented by VIIRS fire products samples the dynamically allocated window size to achieve the best representation of the candidate fire pixel's background. Adjacent pixels are utilized to estimate the radiation signal of potential fire pixels. In addition, effective adjacent pixels in the window centered on potential fire pixels are identified and utilized to estimate the background value. In the case of VIIRS I-bands, the minimum sample size was set to 11 in this study and centered on the candidate fire pixel $\times 11$ element window. The sampling window was allowed to grow to a maximum size of $31 \times 31$ pixels- until at least $25 \%$ of the sample size consisted of effective pixels or at least 10 effective pixels were found. Similar to large-area background sampling applied to daytime data, effective pixels do not include those classified as clouds, water bodies, potential background fires, or pixels with non-zero quality marks on any input band, including pixels with filled values. If the minimum number of effective pixels cannot be met, the pixel is designated as an "unknown," indicating that the background condition could not be correctly characterized [20].

\subsection{Combined Fire Weight Probability}

\subsubsection{Spectral Test Weight}

In this study, the final fire probability was calculated by analyzing the differences in the spectral probabilities and fire sensitivities under different test conditions. In single-channel parameter selection, the brightness temperatures of channels I4 and I5 $\left(\mathrm{BT}_{4}, \mathrm{BT}_{5}\right)$ and the differences between them $\left(\Delta \mathrm{BT}_{45}\right)$ were the major analytical parameters. Figure 1 displays the light temperature characteristic curve of fire pixels in the two seasons considered, which was established by taking 30 typical samples for the fire and non-fire cases. As observed from this figure, a significant difference in the brightness temperature in the I4 channel between fire and non-fire pixels existed, leading to the inference that this channel is most suitable for distinguishing pixels containing sub-resolution combustion components from pixels composed of cooler flameless background areas. Here, $\mathrm{BT}_{4}$ is still the basic condition for preliminary judgment and a weight of 0.3 is added to the fire probability.

Theoretically, channel I5 is the major channel for comparison with I4 to separate active fires from their non-fire backgrounds. However, for small fires, the sensitivity of channel I5 was observed to be weak, and its sensitivity in winter was higher than that in summer. The test of channel I5 in the original algorithm was thus changed to adapt to the difference in the test conditions (i.e., weighted by 0.2 in winter and 0.1 in summer) of fire probability. The differential sensitivity for distinguishing between fires and exposed ground heated by the sun was calculated as $\Delta \mathrm{BT}_{45}$ and the characteristic curve of VIIRS data (Figure 1) demonstrated better sensitivity than channel I5. Therefore, a weight of 0.3 was added to the fire probability. 

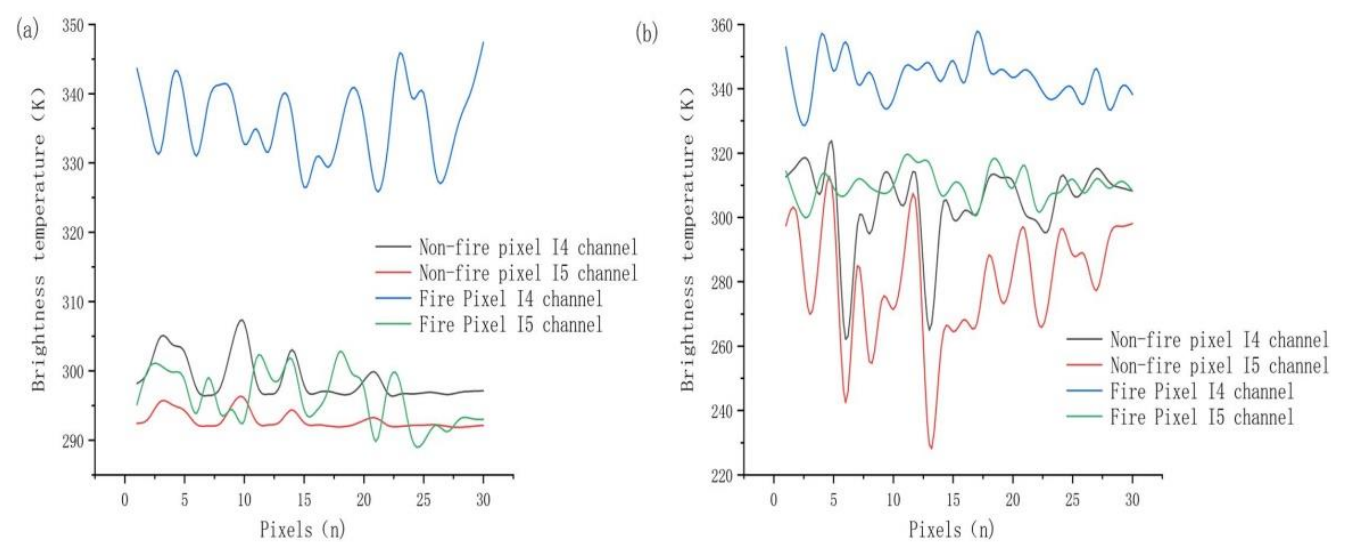

Figure 1. Comparison of brightness temperature between pixel channels I4 and I5. (a) Characteristic curve in winter; (b) characteristic curve in summer. The horizontal axis represents the case number, and the vertical axis represents the brightness temperature of a typical case.

\subsubsection{Contextual Test Weight}

It is impractical to detect clear daytime fire-affected pixels based on the simple fixed threshold applied to the brightness temperature data of VIIRS channels I4 and I5, as the spectral characteristics of these channels may lead to a large number of false positives. The initially large sampling area can adapt to changes in background conditions and increase the flexibility of candidate fire pixel selection. The aim of such adaptability is to improve the sensitivity of the algorithm to fires in cold high latitudes and to reduce the false positive rate at low latitudes with warmer backgrounds.

The VIIRS fire product explores the unique radiative characteristics related to active fires and compares them with adjacent pixels without fires, which constitutes the key test conditions for fire identification. When the minimum pixels constructed by the background pixel window are met, the average brightness temperature deviation of the background pixel in I4 and i5 channels is $\left(\overline{B T}_{4 b}, \bar{\delta}_{4 b}\right)\left(\overline{B T}_{5 b}, \bar{\delta}_{5 b}\right)$, as was the difference in brightness temperature between these channels $\left(\Delta \overline{B T}_{45 b}, \bar{\delta}_{45 b}\right)$ using a background sample. Additionally, the mean and mean absolute deviations were calculated for channel I4 brightness temperature data from potential background fire pixels found within the sampling window $\left(\overline{B T}_{4}{ }^{\prime}, \bar{\delta}_{4}{ }^{\prime}\right)$ :

$$
\begin{gathered}
\Delta \mathrm{BT}_{45}>\Delta \overline{B T}_{45 b}+2 \times \bar{\delta}_{45 b} \\
\Delta \mathrm{BT}_{45}>\Delta \overline{B T}_{45 b}+10 \\
\mathrm{BT}_{4}>\overline{B T}_{4 b}+3.5 \times \bar{\delta}_{4 b} \\
\mathrm{BT}_{5}>\overline{B T}_{5 b}+\bar{\delta}_{5 b}-4 \delta_{4}^{\prime}>5 .
\end{gathered}
$$

These tests formed the key fire test conditions in the product. For this part of the test, we only allocated the weight and did not change the factors in the formula. As an important part of the VIIRS fire product, the proportion of weight distributions for each test condition was 0.3 , but for $\mathrm{BT}_{5}$, the test weight was set to 0.1 .

Based on the VIIRS fire product contextual test, we added judgment conditions to expand those already available in order to eliminate the spatial heterogeneity of fire detection. The differences in the brightness temperature between potential fire and background pixels in channels I4 and I5 were $\Delta \mathrm{BT}_{4}$ and $\Delta \mathrm{BT}_{5}$, respectively, and the difference between potential fire and adjacent background pixels for channels I4 and I5 was $\Delta \mathrm{BT}_{45^{\prime}}$ (Figure 2). In Figure 2a, the surface temperature in winter represents the air and ground temperatures caused by the overall climate, snow cover, and other factors. The special high-temperature conditions of winter fires display the large changes in their difference with respect to the adjacent non-fire pixels in channel I4. These changes were weighted (0.3) into the fire probability. The differences in the information between channels I5 and I4 still revealed this obviously large spatial difference and was also weighted (0.3) into the fire probability. 
However, there was no significant change in the difference between the brightness temperature of fire areas and adjacent non-fire pixels in channel I5, which were similar to the pixel characteristics of adjacent non-fire areas.

(a)

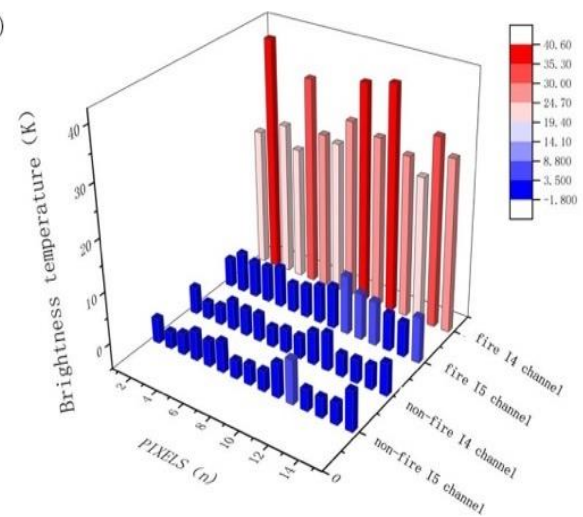

(b)

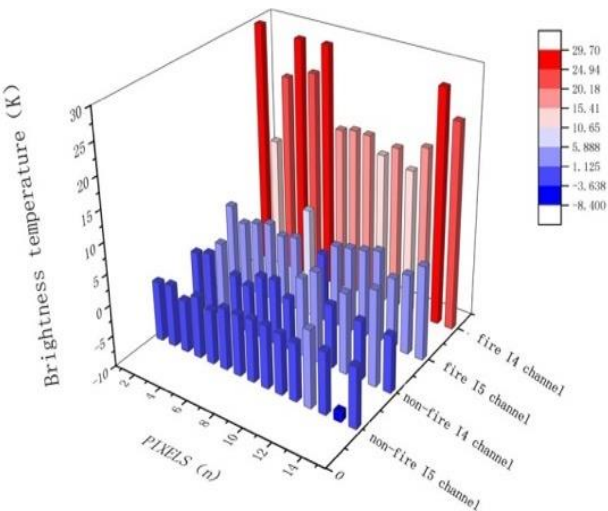

Figure 2. Comparison of differences in the spatial distribution of brightness temperatures between pixel channels I4 and I5 when 15 typical samples were selected. Contextual comparison between channels I4 and I5 of some fire and non-fire pixels (a) in winter; (b) is summer. The $x$-axis is the number of sampled pixels, and the $y$-axis represents the difference in brightness temperature between the potential fire and the effective adjacent pixels in the window.

Channel I5 is a single-gain channel with a saturation temperature of $380 \mathrm{~K}$. For the judgment of small and cold fire pixels, the effect of separating an active fire from its non-fire background is poor. Even in winter, the fire probability weight (0.2) was adjusted. Figure $2 \mathrm{~b}$ displays the contextual comparison of channels I4 and I5 for fire and non-fire pixels of partial sample data in summer. Owing to the influence of sunlight and temperature in summer, the overall surface temperature increased and the difference between the fire and adjacent pixel temperatures decreased significantly. Although the spatial differences in brightness temperatures in the fire areas decreased, they remained obviously different from the non-fire areas. In contrast, the spatial differences in the brightness temperatures of channel I5 were not clear in summer, and the division between fire and non-fire areas was not obvious. The best weight of height differences in channel I4 between fire and background pixels was 0.3 , the best weight for channel I5 was 0.1 , and the best weight for height differences between fire pixels in channels I5 and I4 and the background pixels weight (0.2) which was lower in summer than in winter.

\subsubsection{Weight Calculation}

The temperatures of different underlying surfaces have variable impacts on the results of fire detection. In addition, different algorithms provide unique contributions to the final results, which mostly depend on the accuracy of the tests performed. In this study, the accuracy of the fire detection algorithm was weighted to the results of different tests, and a fire probability diagram was generated. A probability $=1$ denoted a fire point of complete combustion and a probability $=0$ denoted an area without fire. We also limited the results several times, including cloud water discrimination and solar flare removal. The following formula gives the probability $(\mathrm{G})$, wherein $F_{i}$ is the fire detection result, $Q_{i}$ is the corresponding weight of the algorithm, and $N$ is the total number of algorithms.

$$
\mathrm{G}=\frac{\sum_{i=1}^{N} Q_{i} F_{i}}{\sum_{i=1}^{N} Q_{i}}
$$

\subsection{Optimal Threshold of New Fire}

Threshold selection played a decisive role in the test results. With the improvement of weight calculations, the threshold was required to be updated. To find the best threshold 
for each test, the minimum and maximum values of the corresponding test conditions of the fire pixels were counted, and the threshold changed from the statistical minimum to the maximum at the interval of the corresponding step of the test conditions. With these changes in the threshold, the accuracy and surface misjudgment rate also changed. When the accuracy of the pixel was maximized and resulted in minute impact on the threshold, the corresponding test threshold performed best; when the threshold reached a certain value, the accuracy increased slowly with changes in the threshold, while the misjudgment rate increased significantly with increase in the threshold. The threshold with the lowest misjudgment rate was selected as the best threshold. This method reduced the influence of subjectivity and resulted in reasonable conditions.

\subsubsection{Optimum Spectral Threshold}

Image-based thresholds were used to extract fires in VIIRS fire products. However, by changing the weighted probability, the threshold of fire detection also changed. Therefore, we recalibrated the fire probability threshold based on a sensitivity analysis of 100 fire pixel reference images. To determine the best threshold, we allowed it to vary between 260 and 350 (at an interval of 1) and selected the threshold with the highest overall accuracy (Figure 3). In fire detection, the accuracy rate should be considered, and any increase in accuracy should not be affected by the error rate. We inferred that the best thresholds (highest overall accuracy) of $\mathrm{BT}_{4}$ were $325 \mathrm{~K}$ in winter and $335 \mathrm{~K}$ in summer, while those for $\mathrm{BT}_{5}$ were $295 \mathrm{~K}$ in winter and $306 \mathrm{~K}$ in summer. The optimal thresholds of differential information from the I4 and I5 channels were 32 in winter and 26 in summer. However, these were global optimal thresholds, and different surface types may require the implementation of different thresholds.
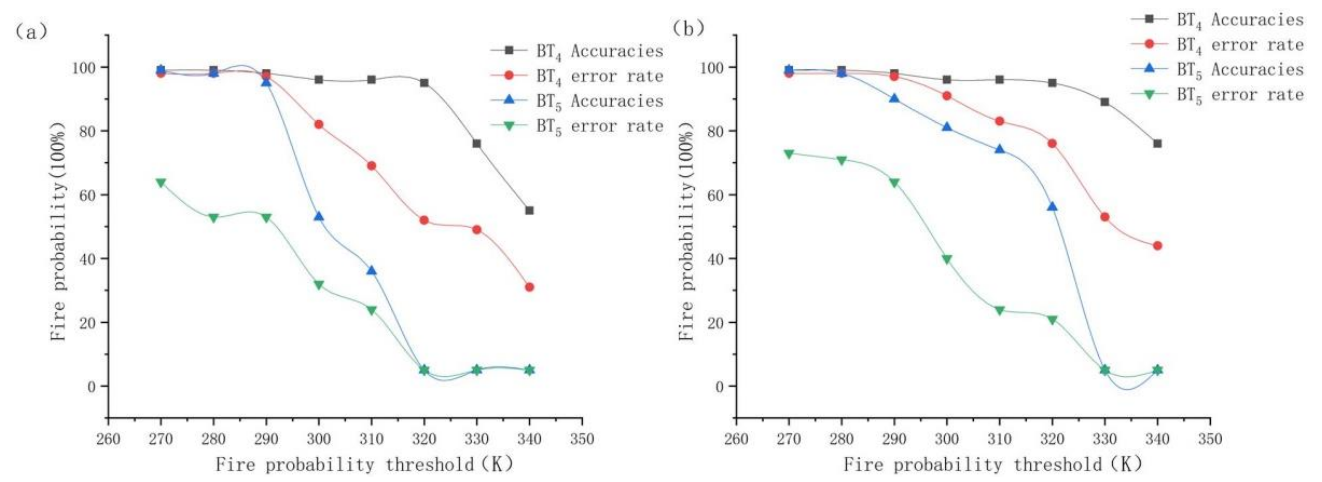

Figure 3. New fire probability thresholds of channels I4 and I5 in (a) winter; (b) summer. The $x$-axis represents the range in threshold variation and the $y$-axis represents the corresponding fire probability. The error rates are also shown.

\subsubsection{Optimal Contextual Threshold}

Under the original spatial test conditions of the VIIRS fire products, the central fire pixel should be greater than the sum of the mean and deviation of adjacent pixels. This condition has important implications for fire alarms, but the difference in fire sensitivity under different conditions should be reconsidered. In this study, weight calculations were added to the spatial comparisons, from which the test conditions were corrected, and the fire probability threshold was calibrated with a test fire point (Figure 4). Nevertheless, it remains necessary to determine the optimal threshold of the parameters in combination with the error rate. As the I5 channel does not exhibit obvious differences in the window as displayed in Figure 4, the optimal threshold was not selected, and complex changes were observed. Ultimately, the 5-K threshold of the product was implemented. Meanwhile, for channel I4, the test condition threshold was $11 \mathrm{~K}$ in winter and $13.5 \mathrm{~K}$ in summer. The threshold for the test conditions of the difference between channels I4 and I5 was $14 \mathrm{~K}$. However, it was obvious that the accuracy of the best threshold selected in summer was 
lower than that in winter, and the difference in sensitivity required compensation via the aforementioned weight calculations.
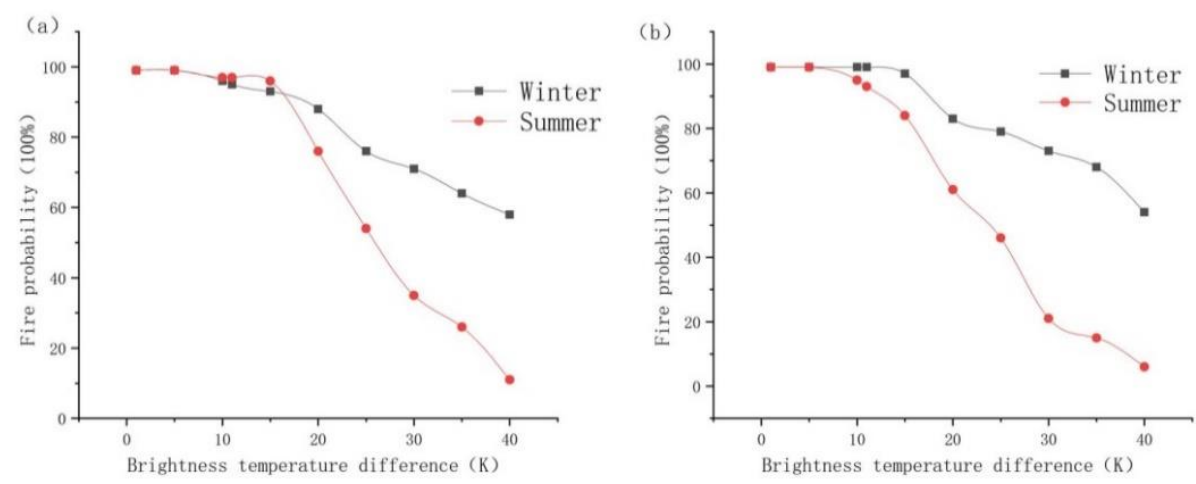

Figure 4. Comparison of brightness temperature thresholds of channels I4 (a) and I4-I5 (b). The $y$-axis shows the difference in the brightness temperature between the fire pixels in the centers of each channel and the adjacent effective pixel in the window, and the $x$-axis shows the fire probability.

\section{Results and Discussion}

Most of the "true" fires provided in the fire verification incorporate the currently utilized fire products and fire databases as reference data. However, the small fires detected in this paper are characterized by a small over fire area and short combustion time. The fire database or fire products are not suitable for verifying the detection of small fires based on VIIRS data, high-resolution data (Landsat 8 OLI) as a visual interpretation. In addition, an imaging time difference with VIIRS data is observed, and the burning time of crops is short. This difference in imaging time makes Landsat 8 unable to be utilized as validation data. In order to verify the identification of small fires by the improved algorithm, the fire was tracked manually. Due to the problem of labor cost, a typical area is selected in the East Asia $\left(34^{\circ} 22.9^{\prime}-38^{\circ} 24.01^{\prime} \mathrm{N}, 114^{\circ} 47.5^{\prime}-122^{\circ} 42.3^{\prime} \mathrm{E}\right)$. The tracking periods were considered from 1 October to 30 December 2020 (winter) and from 1 June to 30 June 2021 (summer). We compared previous VIIRS fire products and analyzed the characteristics of the fires. Each fire event was manually verified, as displayed in Figure 5, and the results of algorithm comparisons are presented in Table 2 . The verification work carried out in this study aims to test the improved algorithm in the detection of small crop combustion fire. The global VIIRS fire products are utilized for comparison, and the fire characteristics are analyzed. Compared with global products, the improved algorithm has a high miss rate of $66.66 \%$ and an error rate of $96.55 \%$ in summer in crop combustion fires in the Far East. The improved algorithm is more sensitive to small fires, the accuracy has been improved, and the miss rate has decreased to $46.15 \%$. In order to accurately demonstrate the accuracy difference between the improved algorithm and the global VIIRS fire products, the missing fire points of VIIRS fire products are extracted and analyzed in different seasons to exhibit the advantages of the improved algorithm. 


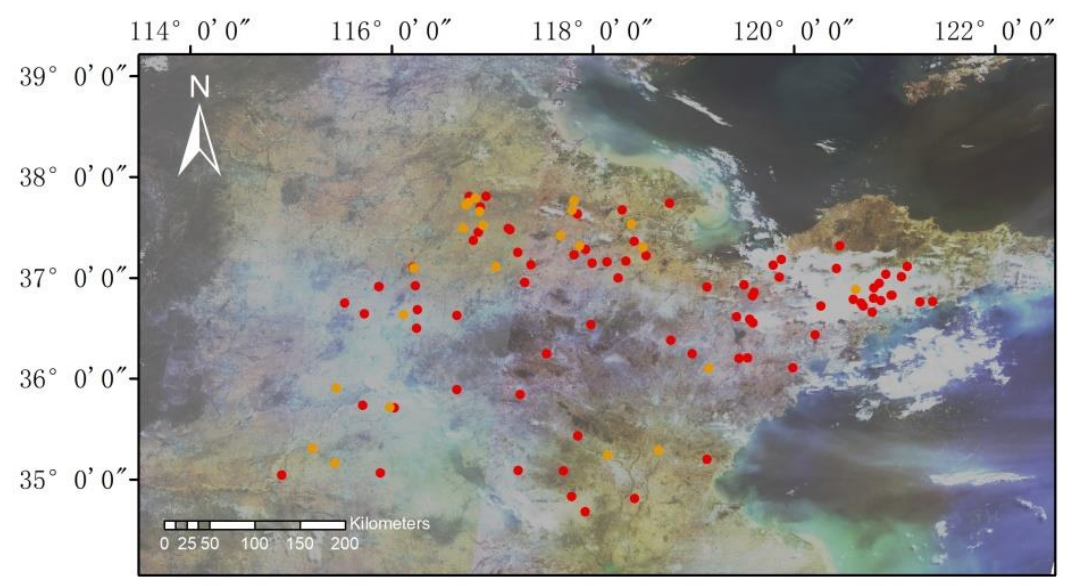

Figure 5. Map displaying sites of manual fire validation in eastern China in winter (Red) and summer (Orange).

Table 2. Comparison of algorithm accuracy.

\begin{tabular}{ccccc}
\hline Algorithm & Season & Accuracy & Omission Rate $^{\mathbf{2}}$ & Error Rate $^{\mathbf{3}}$ \\
\hline Improved algorithm & \multirow{2}{*}{ summer } & $53.85 \%$ & $46.15 \%$ & $36.36 \%$ \\
VIIRS fire products & & $33.33 \%$ & $66.66 \%$ & $96.55 \%$ \\
\hline Improved algorithm & \multirow{2}{*}{ winter } & $73.53 \%$ & $26.47 \%$ & $67.11 \%$ \\
VIIRS fire products & & $56.71 \%$ & $43.28 \%$ & $64.48 \%$ \\
\hline
\end{tabular}

${ }^{1}$ Ratio of the number of real fires detected to the number of actual fires. ${ }^{2}$ Ratio of the number of undetected fires to the actual number of fires. ${ }^{3}$ Ratio of the number of detected non-fires to the number of detected fires.

\subsection{Comparison of Algorithms in Summer}

During the summer detection period, six fire points were selected from the fires not detected by the VIIRS fire products (Table 3). Taking Point 1 as an example, the improved algorithm detected a thermal anomaly at 4:42 on 19 June 2021, but no fire was detected in the VIIRS fire products. Upon field investigation, a fire was confirmed. In Table 3, the $\mathrm{BT}_{4}$ and $\mathrm{BT}_{5}$ of fire Point 1 exhibited an obvious trend towards high temperatures and the brightness temperatures of the potential fire pixels in the I4 and I5 channels were $35.52 \mathrm{~K}$ and $7.41 \mathrm{~K}$ higher than those of the adjacent pixels. The fire at this location was obvious. However, the judgment value of $\Delta \mathrm{BT}_{45}{ }^{\prime}$ in the VIIRS fire product algorithm was high, resulting in a thermal anomaly that could not meet this test requirements and was therefore eliminated. At 5:36 on 19 June 2021, the brightness temperatures of the I4 channel at points 2,3 , and 4 were very high. The potential fire pixel values of the I4 channel were more than $30 \mathrm{~K}$ higher than those of the surrounding pixels. It was verified from field investigations that a fire occurred. It can be inferred from the information in Table 3 that these fire points were also observed in channel I5, wherein the potential fire pixels were close to the surrounding pixels and the difference in their brightness temperatures did not exceed the $5 \mathrm{~K}$ required in the VIIRS fire product algorithm. Thus, it was ignored. Through improved identification, the judgment weights of the potential fire pixels and adjacent pixels of fires in points 2, 3, and 4 in the I5 channel only accounted for 0.1. After the calculation, the probability of such fires was $99.9 \%$. As VIIRS fire products have been developed globally, such a small fire will fall victim to omission errors owing to the limitations of certain test conditions. In contrast, the improved algorithm allowed for the clear identification of small fires. 
Table 3. Fires missing from summer VIIRS fire products that were recovered by the improved algorithm.

\begin{tabular}{|c|c|c|c|c|c|c|c|c|c|}
\hline Point & Time & Position & Area $\left(\mathrm{m}^{2}\right)$ & $\mathrm{BT}_{4}(\mathrm{~K})$ & $\mathrm{BT}_{5}(\mathrm{~K})$ & $\Delta \mathrm{BT}_{45}(\mathrm{~K})$ & $\Delta \mathrm{BT}_{4}(\mathrm{~K})$ & $\Delta \mathrm{BT}_{5}(\mathrm{~K})$ & $\Delta \mathrm{BT}_{45^{\prime}}(\mathrm{K})$ \\
\hline 1 & $\begin{array}{c}2021.06 .19 \\
(04: 42)\end{array}$ & $117.03,37.10$ & 6500 & 345.12 & 309.59 & 35.52 & 17.04 & 7.41 & 9.62 \\
\hline 2 & & $118.49,37.30$ & 6400 & 336.82 & 306.51 & 30.30 & 21.67 & 1.41 & 20.25 \\
\hline 3 & 2021.06 .19 & $116.22,37.09$ & 10,000 & 342.23 & 302.29 & 39.94 & 27.16 & 1.67 & 25.48 \\
\hline 4 & (05:36) & $116.11,36.63$ & 19,000 & 343.49 & 309.19 & 34.29 & 23.95 & 3.19 & 20.75 \\
\hline 5 & $\begin{array}{c}2021.06 .20 \\
(05: 18)\end{array}$ & $118.15,35.23$ & 10,000 & 357.88 & 300.83 & 57.05 & 35.21 & 2.91 & 32.29 \\
\hline 6 & $\begin{array}{c}2021.06 .19 \\
(04: 42)\end{array}$ & $118.65,35.28$ & 7000 & 357.88 & 300.83 & 57.05 & 35.21 & 2.91 & 32.29 \\
\hline
\end{tabular}

\subsection{Comparison of Algorithms in Winter}

Surface temperatures were lower in winter than in summer, as were the brightness temperatures of the thermal anomaly points. Four fire points were selected for a case study in fires that were left unidentified by the winter VIIRS fire products (Table 4). Taking the fire Point 1 at 4:24 on 7 October 2020 as an example, on-site validation demonstrated that the identification of the improved algorithm was correct. A fire had occurred here, but it was not identified in the product. Fire Point 1 was observed in channel I4, and the brightness temperature was high, reaching $342.46 \mathrm{~K}$. The brightness temperature of potential fire pixels was $35.13 \mathrm{~K}$ higher than those of the adjacent pixels, and the fire characteristics were obvious. However, because the brightness temperature of the I5 channel was close to those of the surrounding pixels, the fire was eliminated from the data, resulting in an omission error. For the Point 4 fire at 6:12, the brightness temperature of channel I5 was only $277.27 \mathrm{~K}$, which also resulted in the rejection of the VIIRS fire products. Nevertheless, according to the brightness temperature of channel I4, it can be observed that there a thermal anomaly existed at this location and the potential fire and adjacent pixels of channels I4 and I5 met the conditions for fire determination. It was also confirmed by field investigation that a fire had occurred. The improved algorithm compensated for the uncertainty of the channels and identified the fires with an accuracy of $>95 \%$, allowing for the accurate identification of these small fires.

Table 4. Fires missing from the winter VIIRS fire products that were recovered by the improved algorithm.

\begin{tabular}{|c|c|c|c|c|c|c|c|c|c|}
\hline Point & Time & Position & Area $\left(\mathrm{m}^{2}\right)$ & $\mathrm{BT}_{4}(\mathrm{~K})$ & $\mathrm{BT}_{5}(\mathrm{~K})$ & $\Delta \mathrm{BT}_{45}(\mathrm{~K})$ & $\Delta \mathrm{BT}_{4}(\mathrm{~K})$ & $\Delta \mathrm{BT}_{5}(\mathrm{~K})$ & $\Delta \mathrm{BT}_{45^{\prime}}(\mathrm{K})$ \\
\hline 1 & & $117.32,36.95$ & 13,000 & 342.46 & 299.83 & 42.63 & 35.13 & 2.93 & 32.19 \\
\hline 2 & $\begin{array}{l}2020.10 .07 \\
(04 \cdot 24)\end{array}$ & $116.02,35.71$ & 1300 & 339.1492 & 298.66 & 40.48 & 25.25 & 0.64 & 24.61 \\
\hline 3 & & $117.27,35.84$ & 10,000 & 331.0194 & 293.86 & 37.15 & 24.38 & 1.19 & 23.19 \\
\hline 4 & $\begin{array}{c}2020.12 .15 \\
(06: 12)\end{array}$ & $116.93,37.81$ & 1400 & 329.0843 & 277.27 & 51.81 & 39.46 & 5.09 & 37.37 \\
\hline
\end{tabular}

The characteristics of small cold fires not detected by VIIRS fire products are listed in Tables 3 and 4 . These fires were seriously affected by seasonal images and show different brightness temperatures in different seasons. Additionally, it was difficult to distinguish potential fire pixels from the surrounding pixels using channel I5. Therefore, in the improved algorithm, it was deemed reasonable to set the weight according to the sensitivity of the fire characteristics and test conditions in the area, which compensated for the differences in some of the radiative conditions of small fires.

\section{Conclusions}

According to the seasonal analysis of small fires caused by crop combustion in the Far East, this study introduces a fire detection algorithm based on VIIRS data and verifies the accuracy of the detection algorithm. We aim to provide fire management and environmen- 
tal protection personnel in the East Asia with detection data for small fires caused by crop combustion. This study introduces an improved small fire detection algorithm based on VIIRS data and validates its accuracy. A basic contextual structure of a fire detection algorithm similar to a medium-resolution imaging spectrometer already exists. At this stage, the detection model conducts a hierarchical judgment based on the contextual structure. The intersection of various test results causes the loss of some fire information. To ensure that small fires are not lost during hierarchical judgment, the new algorithm introduces a weight calculation, which is divided according to the difference in fire sensitivity under different test conditions. According to the calculated changes in weight, the fixed threshold was outdated, and the global thresholds for winter and summer were reestablished. During the simulation process, when the accuracy of fuzzy pixels was maximized and minimally affected by changes in threshold, the corresponding reflectivity was determined to be the best threshold for detecting fires. Through comparisons between manual field-validated data and VIIRS fire products, the accuracy of the new algorithm reached $53.85 \%$ in summer and $73.53 \%$ in winter and the overall detection effect was stable.

The small-scale fire explored in this study demonstrates high combustion frequency and wide impact range, which has brought some difficulties to environmental governance. However, due to the wide distribution of fire and difficult supervision, the support of remote sensing technology has solved the governance problem. Moreover, due to the difficulty in selecting this type of fire samples, only the data of the Far East have been studied and verified. Analyses of change based on change detection cannot fully illuminate the relationship between many multitemporal images or separate the coverage conditions and subtle or long-term changes under climate change from background noise. After long-term detection and fire data selection, we can gradually analyze the fire temperature characteristics of various regions and establish a global algorithm model.

Author Contributions: Conceptualization, N.Z. and L.S.; methodology, L.S.; software, N.Z.; validation, N.Z., Z.S. and Y.Q.; formal analysis, N.Z.; investigation, N.Z.; resources, L.S., Z.S. and Y.Q.; data curation, N.Z.; writing—original draft preparation, N.Z.; writing-review and editing, N.Z., L.S., Z.S. and Y.Q. All authors have read and agreed to the published version of the manuscript.

Funding: This research was funded by National Natural Science Foundation of China (41171408); National Key Research and Development Program (2019YFE0126700).

Data Availability Statement: The data presented in this study are available on request from the co-first authors.

Conflicts of Interest: The authors declare no conflict of interest.

\section{References}

1. Natarajan, M.; Pierce, R.B.; Schaack, T.K.; Lenzen, A.J.; Al-Saadi, J.A.; Soja, A.J.; Charlock, T.P.; Rose, F.G.; Winker, D.M.; Worden, J.R. Radiative forcing due to enhancements in tropospheric ozone and carbonaceous aerosols caused by Asian fires during spring. J. Geophys. Res. 2008, 117, D06307. [CrossRef]

2. van der Werf, G.R.; Randerson, J.T.; Collatz, G.J.; Giglio, L.; Kasibhatla, P.S.; Arellano, A.F.; Olsen, S.C.; Kasischke, E.S. ContinentalScale Partitioning of Fire Emissions During the 1997 to 2001 El Niño/La Nina Period. Science 2004, 303, 73-76. [CrossRef]

3. Voulgarakis, A.; Field, R.D. Fire Influences on Atmospheric Composition, Air Quality and Climate. Curr. Pollut. Rep. 2015, 1, 70-81. [CrossRef]

4. Wang, Z.; Zhao, J.; Xu, J.; Jia, M.; Li, H.; Wang, S. Influence of Straw Burning on Urban Air Pollutant Concentrations in Northeast China. Int. J. Environ. Res. Public Health 2019, 16, 1379. [CrossRef] [PubMed]

5. Davies, D.K.; Ilavajhala, S.; Wong, M.M.; Justice, C.O. Fire Information for Resource Management System: Archiving and Distributing MODIS Active Fire Data. IEEE Trans. Geosci. Remote Sens. 2009, 47, 72-79. [CrossRef]

6. Yang, L.; Wang, J.; Gao, Y.H.; Zhang, Z.J.; Zhan, D.X. Application of remote sensing of FengYun-3 meteorological satellite in forestfire monitoring. Environ. Dev. 2019, 31, 129-131.

7. Giglio, L.; Descloitres, J.; Justice, C.O.; Kaufman, Y.J. An Enhanced Contextual Fire Detection Algorithm for MODIS. Remote Sens. Environ. 2003, 87, 273-282. [CrossRef]

8. Giglio, L.; Loboda, T.; Roy, D.P.; Quayle, B.; Justice, C.O. An Active-Fire Based Burned Area Mapping Algorithm for the MODIS Sensor. Remote Sens. Environ. 2009, 113, 408-420. [CrossRef] 
9. Liu, Z.Y.; Jiang, Y.X.; Shen, Z.Q.; Li, S.; Zhao, X. Discussion on improving monitoring ability of forestfire in China using satellite system. Spacecr. Eng. 2019, 28, 96-100.

10. Kant, Y.; Prasad, V.K.; Badarinath, K.V.S. Algorithm for detection of active fire zones using NOAA AVHRR data. Infrared Phys. Technol. 2000, 41, 29-34. [CrossRef]

11. Kaufman, Y.J.; Justice, C.O.; Flynn, L.P.; Kendall, J.D.; Prins, E.M.; Giglio, L. Potential global fire monitoring from EOS-MODIS. J. Geophys. Res. 1998, 103, 32215-32238. [CrossRef]

12. Dozier, J. A Method for Satellite Identification of Surface Temperature Fields of Subpixel Resolution. Remote Sens. Environ. 1981, 11, 221-229. [CrossRef]

13. Giglio, L.; Kendall, J.D.; Justice, C.O. Evaluation of Global Fire Detection Using Simulated AVHRR Infrared Data. Int. J. Remote Sens. 1999, 20, 1947-1985. [CrossRef]

14. Boles, S.H.; Verbyla, D.L. Comparison of Three AVHRR-Based Fire Detection Algorithms for Interior Alaska. Remote Sens. Environ. 2000, 72, 1-16. [CrossRef]

15. Justice, C.O.; Giglio, L.; Korontzi, S.; Owens, J.; Morisette, J.T.; Roy, D.; Descloitres, J.; Alleaume, S.; Petitcolin, F.; Kaufman, Y. The MODIS Fire Products. Remote Sens. Environ. 2002, 83, 244-262. [CrossRef]

16. Freeborn, P.H.; Wooster, M.J.; Roberts, G.; Malamud, B.D.; Xu, W. Development of a Virtual Active Fire Product for Africa Through a Synthesis of Geostationary and Polar Orbiting Satellite Data. Remote Sens. Environ. 2009, 113, 1700-1711. [CrossRef]

17. Zheng, Y.; Liu, J.; Jian, H.; Fan, X.; Yan, F. Fire Diurnal Cycle Derived from a Combination of the Himawari-8 and VIIRS Satellites to Improve Fire Emission Assessments in Southeast Australia. Remote Sens. 2021, 13, 2852. [CrossRef]

18. Li, F.; Zhang, X.; Kondragunta, S. Biomass Burning in Africa: An Investigation of Fire Radiative Power Missed by MODIS Using the 375 m VIIRS Active Fire Product. Remote Sens. 2020, 12, 1561. [CrossRef]

19. Lasaponara, R.; Cuomo, V.; Macchiato, M.F.; Simoniello, T. A Self-Adaptive Algorithm Based on a VHRR Multitemporal Data Analysis for Small Active Fire Detection. Int. J. Remote Sens. 2003, 24, 1723-1749. [CrossRef]

20. Schroeder, W.; Oliva, P.; Giglio, L.; Csiszar, I.A. The New VIIRS 375m Active Fire Detection Data Product: Algorithm Description and Initial Assessment. Remote Sens. Environ. 2014, 143, 85-96. [CrossRef]

21. Wang, W.; Qu, J.J.; Hao, X.; Liu, Y.; Sommers, W. An Improved Algorithm for Small and Cool Fire Detection Using MODIS Data: A Preliminary Study in the Southeastern United States. Remote Sens. Environ. 2007, 108, 163-170. [CrossRef]

22. Martin, W.H.; Boyce, S.G. Introduction: The Southern Setting. In Biodiversity of the Southeastern United States Upland Terrestrial Commu-Nities; Martin, I.W.H., Boyce, S.G., Echternacht, A.C., Eds.; John Wiley: New York, NY, USA, 1993 ; pp. 1-46.

23. Stanturf, J.A.; Wade, D.D.; Waldrop, T.A.; Kennard, D.K.; Achtemeier, G.L. Fire in Southern Forest Landscape. In Southern Forest Resource Assessment; Wear, D.N., Greis, J.G., Eds.; Gen. Tech. Rep. SRS-53; United States Department of Agriculture, Forest Service, Southern Research Station: Asheville, NC, USA, 2002; p. 635.

24. Csiszar, I.; Schroeder, W.; Giglio, L.; Ellicott, E.; Wind, B.; Vadrevu, K.P. Active Fires from the Suomi NPP Visible Infrared Radiometer Suite: Product Status and First Evaluation Results. J. Geophys. Res. 2013, in press. [CrossRef]

25. Goldberg, M.D.; Kilcoyne, H.; Cikanek, H.; Mehta, A. Joint Polar Satellite System: The United States next generation civilian polar-orbiting environmental satellite system. J. Geophys. Res. Atmos. 2013, 118, 13463-13475. [CrossRef]

26. Cao, C.; de Luccia, F.J.; Xiong, X.; Wolfe, R.; Weng, F. Early on-orbit performance of the visible infrared imaging radiometer suite onboard the Suomi national polar-orbiting partnership (S-NPP) satellite. IEEE Trans. Geosci. Remote Sens. 2014, 52, 1142-1156. [CrossRef]

27. Wolfe, R.E.; Lin, G.; Nishihama, M.; Tewari, K.P.; Tilton, J.C.; Isaacman, A.R. Suomi NPP VIIRS prelaunch and on-orbit geometric calibration and characterization. J. Geophys. Res. Atmos. 2013, 118, 508-511. [CrossRef]

28. Hutchison, K.D.; Iisager, B.D.; Mahoney, R.L. Enhanced Snow and Ice identificationwiththeVIIRScloudmaskalgorithm. Remote Sens. Lett. 2013, 4, 929-936. [CrossRef]

29. Kopp, T.J.; Thomas, W.; Heidinger, A.K.; Botambekov, D.; Frey, R.A.; Hutchison, K.D.; Iisager, B.D.; Brueske, K.; Reed, B. The VIIRS Cloud Mask: Progress in the First Year of S-NPP toward a Common Cloud Detection Scheme. J. Geophys. Res. Atmos. 2014, 119, 2441-2456. [CrossRef]

30. Stroppiana, D.; Pinnock, S.; Grégoire, J.-M. The Global Fire Product: Daily Fire Occurrence From April 1992 to December 1993 Derived From NOAA AVHRR Data. Int. J. Remote Sens. 2000, 21, 1279-1288. [CrossRef] 